\title{
A physician workforce planning model applied to Canadian anesthesiology: planning the future sup- ply of anesthesiologists
}

\author{
[Un modèle de planification des effectifs médicaux appliqué à l'anesthésiologie \\ canadienne : prévision de l'offre future d'anesthésiologistes]
}

Douglas Craig MD FRCPC, ${ }^{*}$ Robert Byrick MD FRCPC, $†$ Franco Carli MD MPHIL FRCA

Purpose: To examine the supply of physician anesthesia providers necessary to accommodate the previously described clinical and non-clinical service volume needs throughout Canada

Methods: The Canadian Medical Association (CMA) physician database provided baseline specialist anesthesiologists numbers and ages as of January I, 2000. The Royal College of Physician and Surgeons of Canada (RCPSC) provided annual anesthesia certificant numbers for the period 197|-2000. Combining these data with the separately reported estimates of anesthesia provider needs for the years 1999 and 2016, the matching of anesthesia provider supply and demand during the period 2000-2016 was examined.

Results: The CMA database included 2,287 anesthesiologists in Canada on January I, 2000. The needs assessment (clinical and non-clinical) identified the requirement for 2,495 full time equivalent (FTE) anesthesiologists in 1999 and 3,265 in 2016 (31\% increase). Taking into account the ages of current anesthesiologists, the increased future requirements and the current rate of graduation from RCPSC-approved training programs in Canada a deficit of at least 656 FTEs is identified for the period 2000-2016 (average 4 I per year).

Conclusions: Canada has a current shortage of anesthesiologists. Based on the assessment of future needs in Quebec and extrapolated to all provinces, this shortage will worsen, unless Canadian training programs are expanded or other steps are taken to augment the numbers of anesthesia practitioners. Ongoing studies in each province are required to validate and update these conclusions.

Objectif : Vérifier le nombre d'anesthésiologistes nécessaires pour répondre aux besoins pancanadiens de services cliniques et non cliniques décrits précédemment.

Méthode : De la base de données de l'Association médicale cana dienne (AMC), nous avons obtenu le nombre de l'ensemble des spé- cialistes en anesthésiologie et leur âge au I er janvier 2000. Du Collège royal des médecins et chirurgiens du Canada (CRMCC), nous avons eu le nombre de diplômés annuels en anesthésie pour 1971-2000. Nous avons combiné ces données avec les estimations séparées des besoins d'anesthésiologistes pour 1999 et 2016 et nous avons vérifié l'appariement de l'offre et de la demande d'anesthésiologistes pour la période 2000-2016.

Résultats : La base de données de l'AMC comptait 2287 anesthésiologistes au Canada, au ler janvier 2000. L'évaluation des besoins (cliniques et non cliniques) a déterminé qu'il fallait 2495 anesthésiologistes en équivalents temps plein (ETP) pour 1999 et 3265 pour 2016 (31 \% d'augmentation). Si on tient compte de l'âge des anesthésiologistes au travail, l'augmentation des besoins futurs et le taux actuel de diplômes obtenus après une formation approuvée par le CRMCC, un déficit d'au moins 656 ETC apparaît pour la période de 2000-20l6 (4I par année en moyenne).

Conclusion : La pénurie d'anesthésiologistes que connaît actuellement le Canada pourrait s'aggraver si on se fie à l'évaluation des besoins futurs pour le Québec, besoins extrapolés aux autres provinces, à moins que nos programmes ne forment plus de candidats ou que d'autres actions soient entreprises pour augmenter le nombre de praticiens. Des études doivent se poursuivre dans chaque province afin de valider ces conclusions et de les mettre à jour.

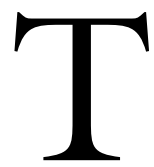

HIS is the second publication arising from a comprehensive study of current and future anesthesia physician resource needs and supply in Canada, sponsored by the Association of Canadian University Departments of Anesthesia (ACUDA). ${ }^{1}$

From the Departments of Anesthesia, University of Manitoba, ${ }^{*}$ University of Toronto, $\dagger$ and McGill University $\ddagger$ Address correspondence to: Dr. D. Craig, Department of Anesthesia, Room LB 315, Health Sciences Centre, 60 Pearl Street, Winnipeg,

Manitoba R3E 1X2, Canada. Phone: 204-787-1518; Fax: 204-787-4291; E-mail: dcraig@hsc.mb.ca Accepted for publication March 28, 2002.

Revision accepted May 30, 2002. 
The first report ${ }^{2}$ identified the need by the year 2016 for 3,265 full time equivalent (FTE) anesthesia practitioners (including specialists and non-specialists) in Canada to accommodate all clinical and non-clinical requirements, taking into account the predicted altered population numbers and demographics (age and sex) at that time. This is a $30.9 \%$ increase from the estimated number of required FTEs in $1999(2,495)$. The 1999 estimate was noted to be in excess of the supply of providers in place at that time.

In this article we examine the large gap between the much higher predicted future needs for anesthesiologists ${ }^{\mathrm{A}}$ in all provinces and the lower current output of Canadian anesthesia residency training programs.

In order to understand anesthesia practitioner supply issues, the manner in which individuals enter clinical practice in Canada must be kept in mind, as well as related factors such as licensing and immigration. Entry into anesthetic practice in Canada occurs via four routes. Most commonly, the graduates of the sixteen Royal College of Physicians and Surgeons of Canada (RCPSC) approved residency training programs obtain their certification in anesthesia and enter practice as specialist anesthesiologists. Some individuals completing these training programs are unsuccessful in the certification examinations and enter anesthesia practice (in some provinces) as non-specialists. A third group is physicians trained as anesthesia specialists in countries other than Canada, who, although not recognized as specialists here, are able to practice (in some provinces) in the same manner as certified specialists. Since practitioners in the second and third categories tend to provide similar volumes of clinical service as certified specialists, their activities are included for analysis with the specialists' grouping. Finally, a significant number of family physicians include anesthesia in their clinical practices. The proportion of anesthetic services provided by family physician anesthesiologists is not known, but is thought to range from about $4 \%$ (Quebec) to about $20 \%$ (Saskatchewan). ${ }^{1}$ Anesthetic services provided by all categories of practitioners must be considered when planning future service delivery in Canada.

Provincial licensing regulations have been the critical limiting point for entry of foreign trained physicians, including anesthetic practitioners, into the Canadian healthcare system. In some provinces, when there has been a demonstrated need for a specific type of physician (in this case, anesthesia practitioner) and if that physician was eligible for a medical license in the province, immigration barriers have not been the limiting factor. However, this has not been the case in most provinces.

The decision of the RCPSC to no longer recognize, as of July 1997, non North American post-medical school training as meeting part of the requirements for its own specialty training programs ${ }^{\mathrm{B}}$ is an important factor which will be examined in more detail in a later section.

\section{Methods}

The estimates of anesthesia provider needs for Canada for the years 1999 and 2016 reported in the first article $^{2}$ arising from the Ryten Report ${ }^{1}$ were used as the base for linking provider supply and demand. The Canadian Medical Association (CMA) physician database provided a count of anesthesiologists as of January 1, 2000. This included data for age as well as location (province) of practice. The RCPSC provided anesthesia certificant numbers for the period 1971-2000.

\section{Results}

\section{Anesthesiologists - 1999-2016}

Table I summarizes the estimates of FTE anesthesiologists required (to accommodate both clinical and non- clinical activities) in each province in 1999 and 2016 and the number of anesthesiologists in place on January l, 2000. The 1999 requirements are based on the Quebec utilization data for 1998-99 plus nonclinical FTE estimates reflecting teaching, research and administrative activities. ${ }^{2}$ The predicted FTE needs for 2016 total 3,265 , a $31 \%$ increase from the January 2000 total of 2,287. Adjustments must be made (see Discussion) for each province, to reflect the volume of services in the province provided by nonspecialist practitioners. The data for $1 / 1 / 2000$ are head counts, while all of the other data are based on estimated FTE requirements.

Table II reports the ages of anesthesiologists in each province as of January 1, 2000. One thousand seven hundred and ten of the 2,287 anesthesiologists graduated from a Canadian medical school while 577 were graduates from medical schools outside of Canada. ${ }^{1}$
A Anesthesiologist refers to a physician who has Royal College of Physicians and Surgeons of Canada (RCPSC) certification in anesthesiology or is recognized as a specialist in his/her province.
B Scott HM. Policy concerning residency training acceptable as prerequisite to specialty certification. Current situation. Royal College of Physicians and Surgeons of Canada. Ottawa, May, 1997. 
TABLE I Number of anesthesiologists in 1999 compared with estimated requirements in 1999 and in the year 2016 - Canada and provinces

\begin{tabular}{|c|c|c|c|c|}
\hline \multirow[t]{3}{*}{ PROVINCE } & \multicolumn{3}{|c|}{ Number of anesthesiologists } & \multirow{3}{*}{$\begin{array}{l}\% \text { Increases in } \\
\text { requirements by } \\
2016\end{array}$} \\
\hline & \multirow{2}{*}{$\begin{array}{l}\text { Head count } \\
1 / 1 / 2000\end{array}$} & \multicolumn{2}{|c|}{ Number of required FTEs } & \\
\hline & & 1999 & 2016 & \\
\hline Newfoundland & 34 & 44 & 49 & $11 \%$ \\
\hline P.E.I. & 6 & 10 & 13 & $30 \%$ \\
\hline Nova Scotia & 92 & 80 & 95 & $19 \%$ \\
\hline New Brunswick & 44 & 59 & 67 & $14 \%$ \\
\hline Quebec & 549 & 606 & 730 & $20 \%$ \\
\hline Ontario & 846 & 960 & 1,305 & $36 \%$ \\
\hline Manitoba & 95 & 96 & 111 & $16 \%$ \\
\hline Saskatchewan & 61 & 83 & 94 & $13 \%$ \\
\hline Alberta & 209 & 229 & 325 & $42 \%$ \\
\hline British Columbia & 350 & 322 & 466 & $45 \%$ \\
\hline Territories & 1 & 6 & 10 & * \\
\hline CANADA & 2,287 & 2,495 & 3,265 & $31 \%$ \\
\hline
\end{tabular}

* Too few to make meaningful calculation. Head count of anesthesiologists (CMA database) on 1/1/2000 excludes the contribution of family physician anesthetists and non-certified anesthetists. The share of anesthesia services delivered by such physicians was not established for all the provinces. It is as low as $4 \%$ in Quebec and as high as $20 \%$ in Saskatchewan (see text).

FTE requirements are calculated as the number of anesthesiologists required to provide service to the population of each province. ${ }^{1,2}$ Some of the clinical services may be delivered in another geographic jurisdiction. No adjustment has been made for this factor.

TABLE II Number of anesthesiologists by province and age. Canada, 1/1/2000

\begin{tabular}{|c|c|c|c|c|c|c|}
\hline \multirow[t]{2}{*}{ PROVINCE } & \multicolumn{5}{|c|}{ Number of anesthesiologists } & \multirow[t]{2}{*}{ Total } \\
\hline & Age $<35$ & Age 35-44 & Age 45-54 & Age 55-64 & Age 65+ & \\
\hline Newfoundland & 2 & 17 & 13 & 1 & 1 & 34 \\
\hline P.E.I. & 2 & 1 & 1 & 1 & 1 & 6 \\
\hline Nova Scotia & 10 & 27 & 31 & 19 & 5 & 92 \\
\hline New Brunswick & 6 & 18 & 10 & 3 & 7 & 44 \\
\hline Quebec & 50 & 195 & 127 & 87 & 90 & 549 \\
\hline Ontario & 54 & 237 & 298 & 156 & 101 & 846 \\
\hline Manitoba & 8 & 30 & 35 & 13 & 9 & 95 \\
\hline Saskatchewan & 0 & 32 & 18 & 9 & 2 & 61 \\
\hline Alberta & 12 & 75 & 90 & 20 & 12 & 209 \\
\hline British Columbia & 16 & 104 & 133 & 75 & 22 & 350 \\
\hline Territories & 0 & 1 & 0 & 0 & 0 & 1 \\
\hline CANADA & 160 & 737 & 756 & 384 & 250 & 2,287 \\
\hline
\end{tabular}

Source: Canadian Medical Association database.

Output from Canadian anesthesia training programs Table III lists the numbers of RCPSC certificants in anesthesia from 1971 to 2000.The lowest "output" was in 1972 (42), the highest in 1986 (118). Since 1989 the number of certificants has never exceeded 100 and has been as low as 73 (1993). The average for 1999-2000 was 85 . The number of certificants each year is the maximum number of new entries into the Canadian workforce, but in reality this maximum will not be achieved. Some certificants enroll in training programs as visa trainees, with the requirement that they return to their home country after completion of their training. Others leave Canada following their training, or do not enter Canadian clinical practice for other reasons. Many who do enter anesthesia practice in Canada will do so as part time anesthesia practitioners.

Number of anesthesiologists required - 2016

Almost 3,300 FTE anesthesiologists will be needed in 2016 to accommodate the clinical and non-clinical needs for all Canada (Table I). If the assumption is made that the services of 200 FTE practitioners will be provided by non-specialists (exact volumes will vary by province), the estimated need for anesthesiologists can be reduced to 3,100 .

Approximately 1,100 of the anesthesiologists in place in January 2000 will reach age 65 by the year 2016, leaving, at most, 1,187 in place (Table II). 
TABLE III Number of certificates in anesthesia awarded by the Royal College of Physicians and Surgeons of Canada, 1971-2000

\begin{tabular}{|c|c|c|c|}
\hline \multirow[t]{2}{*}{ Year } & \multicolumn{3}{|c|}{ Certificants } \\
\hline & Male & Female & Total \\
\hline 1971 & 55 & 12 & 67 \\
\hline 1972 & 37 & 5 & 42 \\
\hline 1973 & 42 & 10 & 52 \\
\hline 1974 & 48 & 7 & 55 \\
\hline 1975 & 49 & 12 & 61 \\
\hline 1976 & 37 & 13 & 50 \\
\hline 1977 & 40 & 10 & 50 \\
\hline 1978 & 53 & 10 & 63 \\
\hline 1979 & 48 & 14 & 62 \\
\hline 1980 & 51 & 19 & 70 \\
\hline 1981 & 60 & 23 & 83 \\
\hline 1982 & 67 & 25 & 92 \\
\hline 1983 & 66 & 25 & 91 \\
\hline 1984 & 72 & 31 & 103 \\
\hline 1985 & 83 & 17 & 100 \\
\hline 1986 & 91 & 27 & 118 \\
\hline 1987 & 86 & 21 & 107 \\
\hline 1988 & 85 & 29 & 114 \\
\hline 1989 & 72 & 29 & 101 \\
\hline 1990 & 73 & 17 & 90 \\
\hline 1991 & 70 & 18 & 88 \\
\hline 1992 & 70 & 28 & 98 \\
\hline 1993 & 57 & 16 & 73 \\
\hline 1994 & 62 & 19 & 81 \\
\hline 1995 & 56 & 19 & 75 \\
\hline 1996 & 58 & 29 & 87 \\
\hline 1997 & 50 & 31 & 81 \\
\hline 1998 & 58 & 22 & 80 \\
\hline 1999 & 63 & 23 & 87 \\
\hline 2000 & 72 & 24 & 96 \\
\hline
\end{tabular}

If 3,100 FTE anesthesiologists will be required in 2016 and approximately 1,100 of the current (January $2000)$ cohort will still be in practice, approximately 2,000 new FTE anesthesiologists will be required, or an average of 125 per year $(2000 \div 16)$.

Since not all graduates of Canadian anesthesia training programs enter clinical practice in Canada, an adjustment to the output figure of 125 is required. If $90 \%$ of program graduates practice for at least ten years, the required average annual output is increased to $139(125 \div .90)$. Adjustment to the entry numbers of trainees will also have to be made since not all training program entrants will complete the program. A very conservative adjustment of a $5 \%$ dropout rate increases the required number of entry positions each year to $146(139 \div .95)$.

The average number of graduates from Canadian anesthesia training programs from 1990 to 1999 was 84 , not all of whom entered clinical practice in Canada (authors' personal observations). If this average output were to continue from 2000 to 2016, and assuming that all new certificants entered full time anesthesia practice in Canada (unlikely) and remained active in full time anesthesia practice (also unlikely), there would be 1,344 FTE additions to the stock of anesthesiologists. Given the estimated need for approximately 2,000 new FTE anesthesiologists over the same time period, a deficit of at least 656 (4l per year) is recognized. As noted, the actual deficit will be much larger, depending on the certificants' initial and continuing anesthesia practice activities, in Canada. The extent to which this minimum deficit will increase and its specific impact in each province and at any point in time can only be determined through the ongoing application, in each province, of the planning model reported.

\section{Discussion}

Canada is now well entrenched in a significant (affecting delivery of clinical services) shortage of anesthesiologists. The ACUDA study ${ }^{1}$ summarized in the earlier article ${ }^{2}$ and the current report provide evidence for not only a continuation of this shortage but a severe worsening, unless changes are made in the near future. Since departure from practice normally depends on age and other personal factors, the solution to the problem must come from increased entry into practice (largest opportunity) and possible changes in the delivery of anesthetic care (small opportunity), both of which are discussed below.

Why did previous anesthesia physician resource studies not predict the problems we have described? First, most previous studies restricted their views to the stock of anesthesiologists - the number of active practitioners in place at a specified point of time - in essence a still photograph. ${ }^{3,4}$ In order to understand the many dynamic factors in play, it is important to examine the flow of anesthesiologists - the ongoing additions and losses to the stock - and, equally important, the reasons for the flows. ${ }^{1,2}$ These will include first time entrants into anesthesia practice (Canadian graduates and graduates of foreign medical schools); re-entrants (many possible reasons); departures (temporary and permanent). Internal migration within Canada is a very important factor in understanding changes in the stock and flow of anesthesiologists in each province. Failure to understand the very specific flow details for each province or areas within a province will lead to faulty conclusions. The importance of using current flow information is also clear. It must be emphasized therefore that the planning model described ${ }^{1,2}$ provided stock information at the point of study and the results of the use of this model must be interpreted with this in mind. Although 
demand projections were made to the year 2016, they must be viewed as illustrations of the use of the model as opposed to definitive numbers. Valid future projections will require future use of the model described.

Second, the traditional use of "head counts" in physician resource planning overlooks the well understood reality that many practitioners (in all specialty and nonspecialty areas) are not in full time clinical practice. It is also recognized that some practitioners work more than a traditional 1.0 FTE position, foregoing vacation for example. At present the national databases tracking Canada's physicians do not report FTE numbers and restrict their data to head counts. In addition to the actual level of professional activity (FTE level), the specific clinical activities of each anesthesiologist are very relevant in workforce planning. Personal factors such as age, gender and health status will be relevant to the individual anesthesiologist's FTE activity, both at a specific point in time as well as changing over time. The extent to which anesthesiologists work in critical care units, acute and chronic pain management, pre-admission clinics and other non operating room areas has been overlooked in anesthesia workforce planning, until recently., 3,5 The assumption that all anesthesiologists provide a 1.0 FTE contribution to the anesthesiology workforce (clinical and/or non-clinical) produces an underestimation of the future deficit. On the other hand, including the anesthetic services provided by non-specialist practitioners in the service volumes requiring anesthesiologists (extent variable between provinces) will lead to an overestimation of the need for anesthesiologists.

Future anesthesia physician resource studies must take into account the specific and current clinical and non- clinical activity patterns of practitioners, in order to arrive at valid measures of the anesthesia provider workforce. This requirement is cumbersome, time consuming and viewed by some as an invasion of privacy, but it is essential if reliable estimates of provider needs are to be available.

A further concern relates to the validity and completeness of the national databases. The data in Table I for the stock of anesthesiologists on $1 / 1 / 2000$ are from the CMA. The second commonly cited source for physician resource data is the Canadian Institute for Health Information (CIHI), which reports as of December $3 \mathrm{I}^{\text {st }}$ each year. The fact that the numbers of physicians listed in these databases are not consistent with each other (in general the CIHI numbers are higher than CMA), or with some provincial databases (in general the CMA numbers are higher than provincial numbers of active clinical practitioners) is widely recognized, but is beyond the scope of this report, other than to recognize its reality.
It is unlikely that the Canadian healthcare system will tolerate the inability to provide required clinical services due to a shortage of Canadian trained anesthesiologists. Are alternatives possible that provide equivalent patient safety and make more efficient use of the physician FTEs available?

Beyond the Canadian anesthesia specialty training programs, the two remaining potential sources of physician practitioners are family physician anesthesiologists and foreign trained anesthesia specialists. Anesthetic practice by family physicians has long been an essential element of the Canadian system. However, the number of family physician anesthetists has declined in recent years. $3,6,7$ The reduction has been reported as $22 \%$ between 1995 and $2000,{ }^{6}$ which followed on a reduction of $32.6 \%$ over the ten years preceding $1996 .^{3}$ The factors leading to this decline need to be understood and adjustments made, where possible. Unfortunately, only incomplete and limited data are available to permit a quantification of the role family physician anesthetists play in Canada. The ACUDA report ${ }^{1}$ includes estimates (based on billing information) of the volumes of work by family physician anesthetists in Quebec (189 physicians doing the work of 23 FTE anesthesiologists) and Ontario (468 physicians with work volume of 80 FTE anesthesiologists). Regardless of the service volume data for all provinces, it is likely that very little of the projected provider shortfall during the period 2000-2016 can be accommodated by this route.

Twenty-five percent $(577$ of 2,287$)$ of the anesthesiologists in place in January 2000 were graduates of medical schools outside Canada. Many of these will have completed their specialty training in Canada, some in another country. A common pattern for the entry of these individuals into the Canadian anesthesia workforce was the completion of 12-24 months of specifically designated (by the RCPSC) training in Canada, followed by admission to the RSPSC anesthesia examinations. This path of entry was closed in July 1997, when the RCPSC changed its regulations, eliminating the eligibility of nonCanadian training for credit towards RCPSC specialty training. This change occurred at the very time anesthesia in Canada was at a point of crisis in service delivery, due to inadequate numbers of practitioners. The RCPSC has more recently announced it is considering further revised regulations, which are likely to be intermediate in their net effects between those in place before and after July 1997. ${ }^{\mathrm{B}}$ The effects of this change on the specialty of anesthesia are not yet clear. If some foreign training is again recognized, there will again be a need for postgraduate training positions specific to this purpose.

Another pathway for foreign trained anesthesia specialists has been direct entry into clinical practice in 
some provinces. Licensing requirements of most provinces have made it difficult (at best) and impossible (at worst) for practitioners without Canadian training (medical undergraduate and/or specialty) to obtain a permanent license to practice in Canada. The severe shortages of anesthesiologists in some provinces has led to current consideration by the respective provincial Colleges of Physicians and Surgeons of licensing policy changes designed to permit entry of qualified and competent specialist anesthesiologists from other countries. The extent to which this practice will continue must be considered in the ongoing planning processes within each province and on a national basis.

Canada has a long tradition of physician anesthesia providers, which has served our healthcare system well. While we recognize there are limited opportunities to achieve FTE anesthesiologist gains through the appropriate use of non-physician assistance in anesthetic care (see below) we do not support direct nonphysician anesthetic practice in Canada, by nurse anesthetists or anesthesia assistants. We do however call for an examination of the appropriate use in Canada of anesthesiologist-supervised professionals who can, in defined and limited circumstances, assist anesthesiologists in clinical care delivery. Since healthcare is a provincial responsibility in Canada and each province has its own legislation governing the healthcare professions, we recognize that the provinces will have to deal with this issue from their own perspectives. At the same time, the opportunity for a common national approach should not be overlooked.

While advocating strongly for the continuation of physician-provided anesthesia services in Canada we also point out that there are real opportunities for net physician resource savings, through the use of properly trained non-physicians. One example is the role of trained nurse clinicians in pre-admission clinics to provide effective screening and pre-admission educational services, limiting the time necessary for an anesthesiologist to be removed from other clinical services. Nurse clinicians also play valuable roles on both acute and chronic pain services, facilitating effective care while limiting the time requirement for anesthesiologist attendance to a minimum. We feel that more extensive use of these types of appropriate assistants will help reduce the impact of anesthesiologist shortages.

It is essential to accept that the findings and recommendations of the ACUDA report ${ }^{1}$ should be the stimulus and template for further planning within each province. They must not be used as firm and final estimates of the future service requirements and provider supply in each province. Deriving these answers with confidence as to validity will require specific analysis within each province. While the ACUDA report does offer a new methodology to address the question of how many anesthesiologists will we require in the future, it also reminds us that valid answers to this question will only come from dynamic studies, not static observations. The recently announced "Task Force Two" of the Canadian Medical Forum, which will oversee a national physician resource strategy ${ }^{\mathrm{C}}$ may be one mechanism through which the ACUDA study methods can be applied for anesthesia.

Is Canada heading into a deepening crisis in anesthesia physician resources? Yes. Can this crisis be reduced in severity? Yes. A combination of increased numbers of medical student positions and anesthesia training positions, increased immigration of qualified anesthesia practitioners, and small gains from alterations to clinical practice must all be examined, on a most urgent basis.

\section{Acknowledgements}

The ACUDA study was conducted by Ms. Eva Ryten, former Director of Research (retired), Association of Canadian Medical Colleges. The study was supported by the Association of Canadian University Departments of Anesthesia and the Anesthesia Section of the Ontario Medical Association. Information about the number of Anesthesia certificants was provided by the Royal College of Physicians and Surgeons of Canada.

\section{References}

1 Ryten E. A physician workforce planning model for the specialty of anaesthesia: theoretical and practical considerations. Association of Canadian University Departments of Anesthesia.

http://www.anesthesia.org/acuda/en/ryten.html

2 Byrick RJ, Craig D, Carli F. A physician workforce planning model applied to Canadian anesthesiology: assessment of needs. Can J Anesth 2002; 49: 663-70.

3 Donen N, King F, Reid D, Blackstock D. Canadian anesthesia physician resources: 1996 and beyond. Can J Anesth 1999; 46: 962-9.

4 Byrick RJ, Craig DB. Consequences of inadequate Canadian physician resource planning (Editorial). Can J Anesth 1999; 46: 913-8.

5 Royal College of Physicians and Surgeons of Canada. 1995 RCPSC Specialty Physician Workforce Study. Ottawa, Ontario. May, 1996.

6 Seal RF. Crisis in rural anesthesia (Editorial). Can J Rural Med 2001; 6: 241-3.

C New Co-Chair for Task Force. CMA Interface. January 8, 2002 (http://www.cma/ca/cmainterface). 
7 Society of Rural Physicians of Canada. Joint position paper on training for rural family physicians in anesthesia. November, 2001.

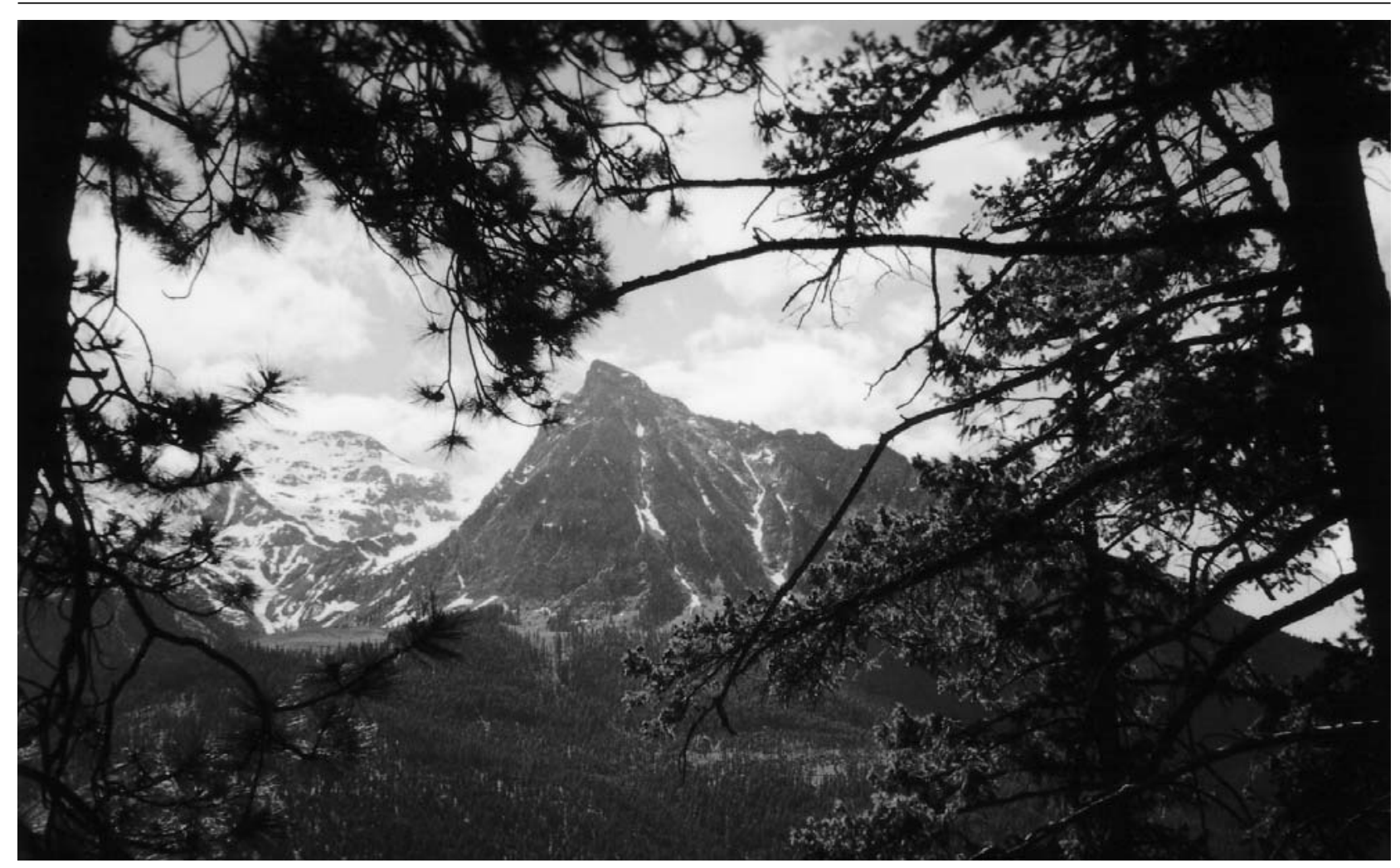

The Rocky Mountains 